\title{
Digital Literacy for Electronic Encyclopedias
}

\author{
JENNIFER L. BRANCH \\ School of Information Science and Policy, \\ University at Albany, State University of New York, \\ Albany, New York \\ ibranch@albany.edu
}

\begin{abstract}
The purpose of this research was to examine the information-seeking processes employed by junior high school students from Inuvik, Northwest Territories, Canada when using CD-ROM encyclopedias. The study revealed that participants needed both instruction and practice to develop the skills and strategies needed for full-text searching of CD-ROM encyclopedias. The participants tended to use search terms only from the original question, had difficulty selecting topics and articles from the retrieved list, and did not read long articles as carefully as short articles. Instruction related to informationseeking skills and strategies should focus on generating search terms, selecting topics from a retrieved list, and, skimming and scanning through text to find the answer.
\end{abstract}

\section{INTRODUCTION}

\section{Digital Literacy For Electronic Encyclopedias}

A recent article in School Library Journal called "Life Among the Laptops" described the following search process:

Shortly after class ended, Ellen logged on to her laptop computer. She checked our school library's online catalog for holdings on her topic. Then, she conducted a similar search of the Houston Public Library's online catalog, as well as the online catalogs of local university libraries. She also searched Amazon.com, reading its reviews of some of the materials she had found, and hunting for additional titles that might be helpful. Finally, she checked our periodical indexes, on the lookout for relevant articles (Weathers, 2001).

This is digital literacy and it is happening at a school library near you. But not every student will be as adept as Ellen at making their way through the masses of information available online. According to Weathers, a school library media specialist, one of her biggest challenges has been "helping students sort through an abundance of resources and evaluate the best materials for their needs (rather than merely helping them locate materials)" (2001, p. 59).

The purpose of this research was to examine the information-seeking processes employed by junior high school students when using CD-ROM encyclopedias. Because such a large amount of information is available to students, the program in school libraries 
must deal with helping students recognize, select and use information that most meets their needs (Baumbach, 1990). In junior high, students' classroom work requires them to access much more information than any time previously in their school career. Students at this age can begin to gain some independence when searching for information.

CD-ROM encyclopedias were used as a stable environment in which to closely examine what it is that students do when searching for information in an electronic environment. The participants in the study were junior high students from Inuvik, Northwest Territories, Canada. The participants, selected by their teachers, ranged in age from 11 to 15 and differed in academic abilities, in experiential and cultural backgrounds, and in knowledge of computers and CD-ROM encyclopedias. A majority of the students were of Aboriginal descent, that is, Inuvialuit, Gwich'in or Cree.

\section{$\underline{\text { Review of the Literature }}$}

Many models to describe information-seeking behaviour have been developed by researchers in various disciplines. Researchers have proposed several information-seeking models that have direct relevance to this study. Bates (1989) argued that her "berrypicking" model of information seeking "is much closer to the real behaviour of information searchers" (p. 407). This dynamic model stressed that real searchers, rather than finding information using one single search query, gather the bits and pieces of information in a "berrypicking" manner. Kuhlthau's work presented another process approach to information seeking (Kuhlthau, 1983, 1988, 1991, 1993). This Information Search Process (ISP) model included affective, cognitive and physical aspects of the whole information-seeking process. It was the inclusion of all three aspects that, for Kuhlthau (Gross, 1991), was "necessary for a model to address a wider, holistic view of information use" (p. 362). Gross' work "emphasized that information seeking may be either self-generated (internally motivated by the personal context) or imposed (set in motion by someone else)" (Gross, 1999, p. 501). This is an important consideration as their subject teacher may have imposed many of the questions that students bring to school library.

Researchers have tried to determine what it is that novice users do when accessing information in electronic environments (Fidel, 1984; Solomon, 1993; Tenopir, NahlJacobovits, \& Howard, 1991; Trivison, Chamis, Saracevic, \& Kantor, 1986). Oliver \& Oliver (1996) suggested that new skills are needed to find information in these new environments and the skills necessary are quite different from the ones needed when using traditional sources. The researchers also reported that these specific skills did not develop from personal exploration of the system. They suggested the three main problem areas in the use of electronic information in schools and school libraries are disorientation, navigation inefficiency and cognitive overload.

Without intervention by a teacher or teacher-librarian, Fidel (1991a, 1991b, 1991c) found that novice users lacked the ability to form effective search plans and to select correct search keys. Trumball, Gay and Mazur (1992) stated that novice users "have only impoverished strategies for synthesizing data into patterns" (p. 315). Pappas \& Geitgey (1994) observed that novice user's information-seeking strategies might be at any point on the simple to complex continuum. Most students left to their own failed to progress to a more analytical search strategy. 
Marchionini (1989) contended that users of information technology are required to deal with finding too much information and so need different skills to deal with refining and selecting appropriate articles. Gross (1999), in her study of imposed queries in three school libraries, found that "in using resources, students had trouble finding answers when they had to search through a lot of text [and] when the resources did not use the same terminology they were given in class" (p. 513). Hirsh (1999) explored the relevance criteria and information seeking of ten fifth-grade children using the OPAC, the Internet, World Book Encyclopedia, and SIRS magazine index. Participants reported that they relied on teachers, librarians, and peers for help in finding information. Librarians were asked for help with search terms, search strategies and locating materials. Fidel et al. (1999) studied searching behaviour of eleventh- and twelfth-grade high school students on the Internet. Like Hirsh, Fidel et al. found that searching was a social and academic experience for students.

Bilal (2000) reported the results of the first part of a research project that looked at 22 grade-seven students' use of the Yahooligans! Web Search for fact-based search tasks. Bilal found that those children who used only single or multiple concepts alone were more successful than those who used single or multiple concepts as well as natural language phrases. Scrolling, use of the back button, and navigating links were three important physical behaviours that all students used.

\section{METHODOLOGY}

This research was conducted within the qualitative paradigm as it was concerned both with process and meaning. In this research, junior high students (grades 7,8 and 9) and members of the school community from Inuvik, Northwest Territories, Canada, who could help inform the context were asked to participate. Of special importance were the core classroom teachers who recommended the twelve participants. The participants were selected by the teachers to represent different reading abilities, language and travel experiences, ethnic and Aboriginal backgrounds and a fairly equal gender split. The participants ranged in age from 11 to 15 . Six participants were male and six participants were female. The participants varied in their levels of school achievement with several being at the top of the class and several being identified with special needs. Eight of the participants were Aboriginal; one was Cree, two were Gwich'In and five were Inuvialuit. Six were born in the Northwest Territories, four were born in other parts of Canada, and two were born in other countries (South Africa and the United States). Pseudonyms are used for the participants. A grade-seven core teacher, a grade-eight core teacher, the grade-nine mathematics/junior high computer teacher, and the Library Assistant were the key informants. Discussions were carried out with one key informant on a regular basis to ensure that the interpretation of interviews and observations were correct.

\section{$\underline{\text { Data Collection }}$}

To ensure a rich description and understanding of the complex phenomenon of junior high students' information-seeking processes when using CD-ROM encyclopedias, a variety of data collection procedures were used. See Branch (2000) for a comparison of Think Alouds and Think Afters as methods for this research. A triangulation of data collection methods included verbal protocol analysis (Think Alouds and Think Afters), interviewing, observation, and videotaping. 
In this study, participants were asked to Think Aloud while searching and this talk was recorded. After the search, participants watched a videotape of their search and were encouraged to add any comments about their information-seeking processes at that time. These Think Alouds and Think Afters were recorded using audiotapes. Two tape recorders were set up to record the voices of the researcher and the participant. The researcher used the audiotapes and the videotapes to create the most complete written transcript possible. The transcripts were used as the primary source of data. The Think Alouds and Think Afters were transcribed verbatim from the participants. Additions to the transcripts were made from the videotapes. Information written in brackets explained what the participant was doing. This included what search term was being typed in, what they were looking at or clicking on when making a statement.

Videotaping the computer screen was felt to be very effective based on previous work with another researcher and because it provided a simple way to replay the search for participants so that we could discuss their information-seeking processes. The video camera was positioned behind the participant's left shoulder and only videotaped the screen during searches. The video camera was attached to a large television so that the participant and the researcher could watch a replay of the search during the Think Afters.

The research setting was a small classroom located at a quiet end of the school where there would be few disruptions. Each student came to the research setting three times for three different search sessions. A computer workstation on a movable cart, a television, and a tripod with the video camera were added to the room. The participants were seated at the computer workstation during the searches. The computer had a Pentium processor, with a 12x CD-ROM drive, a colour monitor and speakers.

\section{Introduction to Search Sessions}

Each participant was given a very general introduction to the CD-ROM encyclopedias. The participants explored the search features and the navigation features of each encyclopedia. Any symbols that might be confusing were explained. Microsoft Encarta Encyclopedia Deluxe 2000 was chosen because it is a very popular encyclopedia and earlier versions of this encyclopedia were located in the school and public library as well as some of the classrooms. 1999 World Book (Deluxe) was selected because it has more Canadian content and because the school and public library have multiple sets of the World Book print encyclopedia. None of the participants had prior experience with the CD-ROM version of World Book Encyclopedia. Participants mentioned using other CD-ROM encyclopedias including Grolier and Compton's.

Older participants indicated that they were more familiar with CD-ROM encyclopedias and computers.

The researcher developed questions for search session one. All twelve participants answered the same four search questions:

1. Who was the first woman in space?

2. Describe the cardinal, a bird.

3. Who was the first man in space?

4. Describe the boxer, a dog. 
In Search Session 2, questions were developed by social studies teachers at each grade level based on current areas of study. Participants began searching immediately and did not have a refresher course in navigating the CD-ROM encyclopedias. The grade seven participants answered the following questions:

1. How long is the Alaska pipeline?

2. Who designed the flag of Alaska?

3. What was the population of the capital city of Alaska in 1996 ?

4. In what year did Alaska have a huge earthquake?

The grade eight participants answered the following questions:

1. What is the official language of Egypt?

2. During what years did Ramses II reign?

3. What is the origin of the word pharaoh?

4. Find the flag and the national anthem of Egypt.

The grade nine participants answered the following questions:

1. What is the lift of the Welland Canal?

2. Name a country through which the equator passes.

3. Into what body of water does the Nelson River flow?

4. Name a country through which the Tropic of Cancer passes.

Participants were given a form at the end of Search Session 2 on which to write their own questions for Search Session 3. Several of the participants forgot or lost their question sheets so time was given at the beginning of the session to write down four questions. The participants were able to choose which encyclopedia they would like to use to search for each question. Search Session 3 provided some very interesting approaches to information seeking on CD-ROM encyclopedias. All of the participants generated questions that were important to their personal lives and interests. Most of the questions were ones that could be found in an encyclopedia. The mean amount of time needed to answer their self-generated questions was just over six minutes.

\section{FINDINGS}

Participants in this study all began their search by typing something into the search box. Almost all of these search terms were derived from the words in the question. The search term either retrieved a list of topics or gave the message "no topics found". The latter caused some participants to be frustrated or confused. Some of them asked for help in generating a new search term. When the participants retrieved a list of topics, most skimmed through the list looking for a topic that seemed relevant. When they did not find such an article, some of the participants used a top to bottom strategy. The participants would click on each topic in the list to see if the information was relevant.

Once in an article, participants either skimmed or read the article depending on its length. Several of the participants used highlighted terms as a guide to locate the answers. 
Once in the appropriate article, the participants usually found the answer. The participants tended to perform three main processes. They entered search terms, skimmed through the list of retrieved topics to find a relevant article, and read, skimmed or scanned through article outlines and articles to find the answer. The information-seeking processes were the same over the three search sessions. Navigation and confidence improved over time.

Factors that influenced the information-seeking processes of junior high students were gathered using information from key informants, participants and the observations of the researcher. These factors included such things as finding the right key word or phrase, knowing when to narrow or broaden the search term, having time, patience and persistence when searching. Other factors included previous computer experience, asking questions of others, reading ability, skimming and scanning skills, and having an understanding of information contained on a CD-ROM encyclopedia.

The findings from this study indicate that there is a need for teachers and teacherlibrarians to work with junior high students to help them learn to access information efficiently and effectively. The information-seeking processes observed in this study are consistent with more general information-seeking models. The findings support the work of Bates (1989) who presented a berrypicking model of information seeking. Participants in this study used a variety of techniques to find the answers. They browsed, used the key features of the search by word and search by topic, used the electronic world atlas feature, tried related articles, asked questions of the researcher, looked at animations and pictures, scrolled through photographs of dogs, etc.

The Think Alouds and Think Afters provide support for the findings of Kuhlthau (1991) and her Information Search Process model. Across all searches, and within individual searches, participants followed the affective stages of the model. These feelings included uncertainty, confusion, frustration and doubt, clarity, sense of relief, and satisfaction. Support for the Tenopir et al. (1991) basic cycle of search behaviour was found in the observation, videotaping, and the Think Aloud data from this study. Participants followed the basic cycle and comments from the Think Alouds provided support for the steps which included: seeking assistance, rehearsing instructions, executing instructions, interpreting consequences, emoting to result, and setting a subgoal. Some of the more complex searches demonstrated each of the steps several times. In the simple searches, only a few of the steps were apparent in the Think Alouds. Findings from this study also supported the work of Tenopir et al. (1991) and Bilal (2000) when they noted that participants tended to use the same strategies during searching and that those participants who tended to use simple search terms continued to do so throughout the searches.

The findings of this study also supported the work of Oliver and Oliver (1996) who noted that participants tended to prefer one strategy to others and that those with more computer experience used more options. Most of the participants did not make use of advanced search features. This was in keeping with Hirsch's work. Participants in this study had trouble finding answers when they had to search through a lot of text just like in the work of Bilal (2000) and Gross (1999). Hirsch (1999) and Fidel et al. (1999) found that participants were frustrated when results were not as expected, and this study confirmed that finding. Participants tended to look for the lines in articles that would answer the question and to move quickly between the article, article outline, and search box. 
Implications

This study found that students need teaching to make them better searchers. Teachers and teacher-librarians need to examine how they prepare for, facilitate, and evaluate/reflect on the information-seeking processes of their students in both print and electronic environments. The following recommendations are made in the hopes that they assist teachers and teacher-librarians to help students become more digitally literate.

\section{Preparation}

Practitioners should become familiar with the work of Tenopir et al. (1991), Kuhlthau (1991) and Bates (1989) and other research about the information-seeking processes of children and young adults. Familiarize students with these models and provide opportunities for practice. To prepare for information-seeking situations in classrooms and libraries, practitioners must be prepared to deal with the need of searchers who ask questions. It is important to address the affective behaviours that may occur during searching and to acknowledge that searching for information can be frustrating, confusing, upsetting, exciting, and challenging.

Encourage students to ask others for help when they encounter new vocabulary. Help students to develop strategies and skills to deal with the affective stages of the ISP, that is, uncertainty, optimism, confusion, frustration and doubt, clarity, sense of direction, confidence, and, relief/satisfaction or disappointment. Give students the opportunity to search for information of a personal nature and provide CD-ROM encyclopedias and other materials with a variety of reading levels so that all students can successfully locate information. Before beginning a research project, introduce the topic and new vocabulary to students to ensure adequate prior knowledge. Demonstrate and give time to practice using skimming and scanning techniques, including the use of highlighted search terms as a guide for their scanning/checking, article outlines, indexes, headings, and subheadings. Explain to students the similarities and differences between databases, indexing and abstracting services, CD-ROM encyclopedias, and the Internet.

\section{Facilitation}

When acting as a facilitator for information seeking, support small group and whole group discussions about search terms and search strategies as this may provide new techniques and ideas that are unique to one searcher but may be useful for all. Encourage students to engage in self-talk, talk with peers, or talk with teachers and teacher-librarians during their searches. Allow students with low literacy levels extra time to locate information and expect students to need very different amounts of time to find information. Support students when they feel overwhelmed, confused, frustrated and full of doubt and provide opportunities for students to use information technologies so that their confidence can improve.

Focus on the three domains of human behaviour from the work of Tenopir et al. (1991); the first is the affective domain that controls goal selection; the second is the cognitive domain that determines the strategies necessary to reach goals; and, the third is the sensorimotor domain that implements the physical actions necessary to reach goals. Make sure to provide opportunities for students to learn and practice skills and strategies that they can apply at each step in this cycle. It is also important to focus on the three main search 
tasks, that is, generating search terms, selecting topics from a retrieved list, and, skimming and scanning through text to find the answer. Teach skills and strategies to students to help them generate search terms in a variety of different situations and with a variety of information sources.

\section{Evaluation and Reflection}

When evaluating and reflecting on information seeking, use observation and research to inform practice. Support, and encourage others to support, research projects in local school districts, schools and school libraries. Making elementary, middle, junior and senior high school settings available can enable researchers to carry out studies of importance to teachers and teacher-librarians. Write and report about the interesting observations, strategies, and ideas that are happening in schools and school libraries.

Researchers need to continue work in the area of digital literacy and information literacy research in schools and school libraries. Studies are needed that compare and contrast the information-seeking processes of junior high students as they access information from other reference tools, both print and electronic. Also of interest is observations of students as they complete real assignments, projects and reports with topics selected by the teacher, teacher-librarian or by the students themselves. It is important to move away from a laboratory setting and to a natural group setting in the library or a classroom away. This will allow researchers to observe students as they interact with others, as they would normally do. There must also be an effort to continue to test information-seeking models and theories in real-life settings with school-age participants who come with a variety of backgrounds, experiences, and abilities.

\section{CONCLUSION}

Becoming digitally literate involves much more than just becoming effective users of information found on CD-ROM or online encyclopedias. However, the findings from this study can certainly be used as a basis for helping students develop the skills to help them find information on the Internet and in print resources. Finding the correct search term, knowing when to use broader or narrower terms, skimming and scanning large numbers of topics and large amounts of text, and understanding the materials and information available both online and in print make up the foundations of information literacy.

\section{REFERENCES}

Akin, L. (1998). Information overload and children: A survey of Texas elementary school students. School Library Media Quarterly Online, 1. Retrieved June 2, 2000 from the World Wide Web: http://www.ala.org/aasl/slmq/overload.html.

Anderson-Inman, L., Horney, M. A., Chen, D.-T., \& Lewin, L. (1994). Hypertext literacy: Observations from the ElectroText Project. Language arts, 71, 279-287.

Bates, M. J. (1989). The design of browsing and berrypicking techniques for the on-line search interface. On-line Review, 13 (5), 407-424.

Baumbach, D. J. (1990). CD-ROM: Information at your fingertips! School Library Media Quarterly, 18 (3), 142-149. 
Bilal, D. (1999). Web search engines for children: A comparative study and performance evaluation of Yahooligans, Ask Jeeves for Kids, and Super Snooper ${ }^{\mathrm{TM}}$. In L. Woods (Ed.), ASIS '99: Proceedings of the 62 $2^{\text {nd }}$ ASIS annual meeting (Vol. 36, pp. 70-83). Medford, NJ: Information Today.

Bilal, D. (2000). Children's use of the Yahooligans! web search engine: I. Cognitive, physical, and affective behaviours on fact-based search tasks. Journal of the American Society for Information Science, 51 (7), 646-665.

Bilal, D., \& Watson, J. S. (1998). Children's paperless projects: Inspiring research via the web. In 64th IFLA general conference. Amsterdam: International Federation of Library Associations.

Borgman, C. L, Hirsh, S. G., Walter, V. A., \& Gallagher, A. L. (1995). Children's searching behaviour on browsing and keyword on-line catalogs: The science library catalog project. Journal of the American Society for Information Science, 46 (9), 663-684.

Branch, J. L. (2000). Investigating the information-seeking processes of adolescents: The value of using Think Alouds and Think Afters. Library and Information Science Research, 22 (4), 371-392.

Chelton, M. K., \& Thomas, N. P. (1999). Introduction: Why a special topic issue on youth issues? Journal of the American Society for Information Science, 50 (1), 7-9.

Davidson-Shivers, G. V., Shorter, L., \& Jordan, K. (1997). Children's learning strategies, encoding processes, and navigational decisions in a hypermedia concept lesson. In proceedings of selected research and development presentations at the 1997 national convention of the association for educational technology (pp. 21-29).

Denzin, N. K., \& Lincoln, Y. S. (1998). Collecting and interpreting qualitative materials. Thousand Oaks, CA: Sage.

Fidel, R. (1984). On-line searching styles: A case-study-based model of searching behaviour. Journal of the American Society for Information Science, 35 (4), 211-221.

Fidel, R. (1991a). Searchers' selection of search keys: I. The selection routine. Journal of the American Society for Information Science, 42 (7), 490-500.

Fidel, R. (1991b). Searchers' selection of search keys: II. Controlled vocabulary of free-text searching. Journal of the American Society for Information Science, 42 (7), 501-514.

Fidel, R. (1991c). Searchers' selection of search keys: III. Searching styles. Journal of the American Society for Information Science, 42 (7), 515-527.

Fidel, R., Davies, R. K., Douglass, M. H., Holder, J. K., Hopkins, C. J., Kushner, E. J., Miyagishima, B. K., \& Toney, C. D. (1999). A visit to the information mall: Web searching behavior of high school students. Journal of the American Society for Information Science, 50 (1), 24-37.

Gross, M. (1999). Imposed queries in the school library media center: A descriptive study. Library and Information Science Research, 21 (4), 501-521.

Hirsh, S. (1999). Children's relevance criteria and information seeking on electronic resources. Journal of the American Society for Information Science, 50 (14), 1265-1283.

Huberman, A. M., \& Miles, M. B. (1998). Data management and analysis methods. In N. K. Denzin \& Y. S. Lincoln (Eds.). Collecting and interpreting qualitative materials (pp. 179245). Thousand Oaks, CA: Sage.

Kuhlthau, C. C. (1983) The research process: Case studies and interventions with high school seniors in advanced placement English classes using Kelly's theory of constructs. Ed.D. Dissertation, Rutgers University, New Brunswick, NJ.

Kuhlthau, C. C. (1988). Developing a model of the library search process: Cognitive and affective aspects. Reference Quarterly, 27, Winter, 232-242.

Kuhlthau, C. C. (1991). Inside the search process: Information-seeking from the user's perspective. Journal of the american society for information science, 42 (5), 361-371. 
Kuhlthau, C. C. (1993). Seeking meaning: A process approach to library and information services. Norwood, NJ: Ablex.

Large, A. \& Beheshti, A. (2000). Primary school students' reaction to the web as a classroom resource. In A. Kublik (Ed.), Dimensions of a global information science. Proceedings of the $28^{\text {th }}$ Annual Conference of the Canadian Association for Information Science Edmonton, Alberta: Canadian Association for Information Science. Retrieved from the World Wide Web: http://www.slis.ualberta.ca/cais2000/

Large, A., Behesti, J., \& Breleux, A. (1998). Interface navigation by grade-six students: A case study of three multimedia CD-ROM products. In E. G. Toms, D. G. Campbell \& J. Dunn (Eds.). Information science at the dawn of the next millenium: Proceedings of the 26th Annual Conference of the Canadian Association for Information Science (pp. 289-302). Toronto, ON: CAIS.

Large, A., Beheshti, J., Breuleux, A., \& Renaud, A. (1994a). A comparison of information retrieval from print and CD-ROM versions of an encyclopedia by elementary school students. Information Processing and Management, 3 (4), 499-513.

Large, A., Beheshti, J., Breuleux, A., \& Renaud, A. (1994b). Multimedia and comprehension: A cognitive study. Journal of the American Society for Information Science, 45 (7), 515-528.

Large, A., Beheshti, J., Breuleux, A., \& Renaud, A. (1995). Multimedia in primary education: How effective is it? School Library Media Quarterly, 23 (1), 19-25.

Large, A., Beheshti, J., Breuleux, A., \& Renaud, A. (1996). Effect of animation in enhancing descriptive and procedural texts in a multimedia learning environment. Journal of the American Society for Information Science, 47 (6), 437-448.

Large, A., Beheshti, J., \& Moukdad, H. (1999). Information seeking on the web: Navigational skills of grade-six primary school students. In L. Woods (Ed.), ASIS '99: Proceedings of the $62^{\text {nd }}$ ASIS annual meeting (Vol. 36, pp. 84-97). Medford, NJ: Information Today.

Liebscher, P., \& Marchionini, G. (1988). Browse and analytical search strategies in a fulltext CD-ROM encyclopedia. School Library Media Quarterly, 16 (4), 223-233.

Marchionini, G. (1989). Making the transition from print to electronic encyclopedias: Adaptation of mental models. International Journal of Man-machine Studies, 30, 591-618.

McGregor, J. H. (1993). Cognitive processes and the use of information: A qualitative study of higher-order thinking skills used in the research process by students in a gifted program. $\mathrm{PhD}$ Dissertation. Florida State University.

Oliver, R., \& Oliver, H. (1996). Information access and retrieval with hypermedia information systems. British Journal of Educational Technology, 27 (1), 33-44.

Pappas, M., \& Geitgey, G. (1994). Observing student searches in an electronic encyclopedia. The Book Report, 12 (5), 13-14.

Perzylo, L., \& Oliver, R. (1992). An investigation of children's use of a multimedia CDROM product for information retrieval. Microcomputers for Information Management, 9 (4), 225-239.

Pitts, J. M. (1994). Personal understandings and mental models of information: A qualitative study of factors associated with adolescents' information seeking and use. School Library Media Annual, 12, 200-202.

Schacter, J., K.W.K. Chung \& A. Dorr (1998). Children's internet searching on complex problems: Performance and process analyses. Journal for the American Society of Information Science, 49 (9), 840-849.

Solomon, P. (1993). Children's information retrieval behaviour: A case analysis of an OPAC. Journal of the American Society for Information Science, 44 (5), 245-264. 
Tenopir, C., Nahl-Jakobovits, D., \& Howard, D. L. (1991). Strategies and assessments online: Novices' experience. Library and Information Science Research, 13, 237-266.

Trivison, D., Chamis, A. Y., Saracevic, T., \& Kantor, P. (1986). Effectiveness and efficiency of searchers in on-line searching: Preliminary results from a study of information seeking and retrieving. In ASIS '86: Proceedings of the American Society for Information Science annual meeting 49, 341-349. Medford, NJ: Learned Information.

Trumball, D., Gay, G., \& Mazur, J. (1992). Students actual and perceived use of navigational and guidance tools in a hypermedia program. Journal of Research on Computing in Education, 24 (3), 315-328.

Weathers, B. (2001). Life among the laptops. School Library Journal, 47 (3), 56-60.

Wilson, T. D. (1994). The proper protocol: Validity and completeness of verbal reports. Psychological Science, 5 (5), 249-251. 